\title{
Nanotubular Structures Developed from Whey-Based $\alpha$-Lactalbumin Fractions for Food Applications
}

\section{Özgür Tarhan}

Dept. of Food Engineering, Faculty of Engineering, Izmir Inst. of Technology, Urla Campus, Izmir, TR-35430, Turkey

\section{Şebnem Harsa}

Dept. of Food Engineering, Faculty of Engineering, Izmir Inst. of Technology, Urla Campus, Izmir, TR-35430, Turkey

DOI 10.1002/btpr.1956

Published online August 6, 2014 in Wiley Online Library (wileyonlinelibrary.com)

Whey proteins have high nutritional value providing use in dietary purposes and improvement of technological properties in processed foods. Functionality of the whey-based $\alpha$-lactalbumin $(\alpha-L a)$ may be increased when assembled in the form of nanotubes, promising novel potential applications subject to investigation. The purpose of this study was to extract highly pure $\alpha$-La from whey protein isolate (WPI) and whey powder (WP) and to construct protein nanotubes from them for industrial applications. For protein fractionation, WPI was directly fed to chromatography, however, WP was first subjected to membrane filtration and the retentate fraction, whey protein concentrate (WPC), was obtained and then used for chromatographic separation. $\alpha$-La and, additionally $\beta$-Lg, were purified at the same batches with the purities in the range of 95\%-99\%. After enzymatic hydrolysis, WPI-based $\alpha$-La produced chain-like and long nanotubules with $\sim 20 \mathrm{~nm}$ width while WPC-based $\alpha$-La produced thinner, miscellaneous, and fibril-like nanostructures by self-assembly. Raman and FT-IR spectroscopies revealed that $\alpha$-La fractions, obtained from both sources and the nanostructures, developed using both fractions have some structural differences due to conformation of secondary structure elements. Nanotube formation induced gelation and nanotubular gel network entrapped a colorant uniformly with a transparent appearance. Dairy-based $\alpha-L a$ protein nanotubules could be served as alternative gelling agents and the carriers of natural colorants in various food processes. (C) 2014 American Institute of Chemical Engineers Biotechnol. Prog., 30:1301-1310, 2014

Keywords: whey, $\alpha$-lactalbumin, purification, protein nanotubes, nanotubular gels

\section{Introduction}

Food grade nanoscale structures, such as protein and peptide nanotubes, can be produced by breaking up the bulk materials into molecular units and building up the novel supramolecular structures from these molecules through selfassembly. Molecular self-assembly is a bottom-up approach and can be described by spontaneous association of individual entities into well-defined coherent structures through noncovalent interactions. ${ }^{1}$ This phenomenon is widely recognized in nature. But only in the last decade, it has attracted attention to investigate its use in the design and fabrication of advanced functional nanostructures. ${ }^{2,3}$ The protein-based such nanostructures may have unique properties providing potential applications in food processing. The presented study aimed to investigate whey-based protein nanoparticles developed through molecular self-assembly for industrial applications.

Whey is a valuable dairy by-product due to its proteins especially. Beta-lactoglobulin $(\beta-\mathrm{Lg}, 18.4 \mathrm{kDa})$ and alphalactalbumin $(\alpha-\mathrm{La}, 14.2 \mathrm{kDa})$ account for the main part of

Correspondence concerning this article should be addressed to S.. Harsa at sebnemharsa@iyte.edu.tr. the proteins in whey. ${ }^{4}$ It has been previously reported that, whey $\alpha$-La is capable of forming nanotubular structures by self-assembly process after partial enzymatic hydrolysis. 5,6 These hollow nanotubes are suggested as safe structures having potential applications in food processing for gelation, viscosifying, and encapsulation purposes. ${ }^{7} \alpha$-La nanotubes $(\alpha$-LaNTs) can be considered as significant food nanoparticles with their promising application potential. Therefore, this study was focused on the investigation of protein nanotubules/fibrils to be developed by using $\alpha$-La fractions purified from whey products.

Purification of whey proteins are well documented in the literature. ${ }^{4,8-18}$ Most of them can provide effective purification in the laboratory scale; however, some limitations can also be encountered such as low purity or recovery of the proteins. Preparative scale purification of whey proteins through membrane filtration and ion-exchange chromatography was used to extract proteins with high purity for production at large scale. ${ }^{15,19}$ By considering the current literature, membrane filtration and chromatographic techniques were selected to separate whey $\alpha$-La to be used for nanotube formation.

Protein native structure is prone to the risk of denaturation during the purification processes..$^{20,21}$ In addition, during 
nanotube and fibril formation, structural changes in the protein are also expected due to self-assembly of peptide molecules. Raman and FT-IR spectroscopies can be quite useful for the structural analysis of protein molecules. Some major vibrational modes, named amide I, amide II, amide III, and backbone skeletal stretching modes, of the peptides, observed in the Raman and FT-IR spectra, provide valuable information about conformational changes in the protein secondary structure. ${ }^{20,22}$

Gelation is one of the most important functional properties of food proteins. Whey protein gels obtained by heat and enzymatic treatments are mostly investigated. ${ }^{23-27}$ Partial hydrolysis of $\beta-\mathrm{Lg}$ leads to formation of fibrillar aggregates and gelation. ${ }^{28}$ However, $\alpha$-La nanotubular gels have been reported to be 20 times stiffer than $\beta$-Lg gels. ${ }^{5}$ Thus, the use of $\alpha$-La nanotubular gels may be more desirable for target applications. The presented study also investigated $\alpha$-La gels with the structure of self-assembled nanotubules in relation to application. Stiffer and more viscoelastic gels induced by $\alpha$ LaNTs can be used for the entrapment of some bioactive materials and coloring agents for various food applications. They can be used as safe carriers for target ingredients. These enriched gels can be used for coating purposes and/or can be blended into food composition during processing to improve the functionality of the final products. Besides food applications, nanotubular gels can also be used for some nonfood applications such as scaffolds for biomedical purposes ${ }^{7}$.

The objective of this study was to obtain highly pure $\alpha$-La to use in the development of protein nanotubes for food industry. In this article, we present our studies and discuss our results. The first part of our work is focused on the extraction of $\alpha$-La from whey products, whey protein isolate (WPI), and whey powder (WP) using membrane filtration and chromatographic techniques (anion-exchange chromatography, AEC and size exclusion chromatography, SEC). The second part consists of development of $\alpha$-La protein nanotubes from the purified fractions by self-assembly after partial enzymatic hydrolysis, investigating structure of purified $\alpha$-La proteins and nanotubules using spectroscopy, and $\alpha$-LaNT gelation and entrapment of a colorant within the nanotubular gel matrix. We conclude each part with discussion and comments.

\section{Materials and Methods}

\section{Materials}

Most of the chemicals and standards ( $\alpha$-La, L-6310) were purchased from Sigma Chemicals Co. (St. Louis, MO). Anion exchanger matrix (Q-sepharose) was purchased from Bio-Rad Laboratories (Hercules, CA). WP with $10 \%-12 \%$ protein and $65 \%-75 \%$ lactose content was kindly supplied by a commercial plant (Pınar A.Ş., İzmir, Turkey). Commercial WPI, BIPRO, with $95 \%$ protein and $1 \%$ lactose content was obtained from Davisco Foods Int. (Eden Prairie, MN). Ultrafiltration (UF) membranes and high performance liquid chromatography (HPLC) columns were purchased from Sartorius Stedim Biotech S.A. (Goettingen, Germany) and Agilent Technologies (Santa Clara, CA), respectively. Bacillus licheniformis protease (BLP 2,4 U/g) was kindly provided by Novozymes A/S (Bagsvaerd, Denmark).

\section{Purification of $\alpha$-la from whey preparates}

WPI $(1 \%$, w/v) was dissolved in $0.05 \mathrm{M}$ Tris- $\mathrm{HCl}$ buffer, $\mathrm{pH}$ 6.0. WP $(2.5 \%, \mathrm{w} / \mathrm{v})$ was dissolved in distilled water with the $\mathrm{pH}$ of the solution being 6.33. WPI solution was directly fed to anion exchange column for protein fractionation. However, WP solution (WPS) was first introduced to UF process to eliminate lactose and nontarget small peptides and to concentrate proteins. Then, the resultant retentate fraction containing whey protein concentrate (WPC) was fed to AEC for further fractionation. Ten-kilo dalton-membrane was used for UF. To prevent the formation of fouling layer above the membrane and improve the separation efficiency, diafiltration (DF) was performed by five volumes of distilled water, during the process.

Q-Sepharose, a strong anion exchanger matrix, was packed into a glass column with a $50 \mathrm{~cm}$ length and $2.5 \mathrm{~cm}$ internal diameter. It was equilibrated with $0.05 \mathrm{M}$ Tris- $\mathrm{HCl}$ buffer of $\mathrm{pH}$ 6.0. First, WPI and then WPC solutions were fed to the column. Unbound proteins were eluted with $0.05 \mathrm{M}$ Tris- $\mathrm{HCl}, \mathrm{pH}$ 6.0. Proteins, reversibly adsorbed onto the matrix, were eluted by changing $\mathrm{pH}$ of the buffers. ${ }^{19}$ First, $0.05 \mathrm{M}$ Tris- $\mathrm{HCl}$, pH 5.0 was used to elute $\beta$ - $\mathrm{Lg}$, then, $0.05 \mathrm{M}$ Tris- $\mathrm{HCl}, \mathrm{pH} 4.0$ was used to elute $\alpha$-La. The flow rate was about $0.25-1.5 \mathrm{~mL} / \mathrm{min}$. All fractions were collected by a fraction collector according to changes in the absorbance monitored at $280 \mathrm{~nm}$. The main fractions, collected during elution steps of AEC analysis of WPI and WPC samples, were fed to Sephadex-G75 column, in the respective order, for further purification. Sephadex-G75 gel solution, prepared by swelling of powdered product in $0.05 \mathrm{M}$ Tris$\mathrm{HCl}$ ( $\mathrm{pH}$ 6.0), was packed into the glass column with a $50 \mathrm{~cm}$ length and $2.5 \mathrm{~cm}$ diameter. The column equilibration and elution were performed using $0.05 \mathrm{M}$ Tris- $\mathrm{HCl}$ ( $\mathrm{pH}$ 6.0) buffer. The flow rate was about $1.5-2 \mathrm{~mL} / \mathrm{min}$. The high volume fractions were concentrated using $10-\mathrm{kDa}$ UF membrane and $5-\mathrm{kDa}$ centrifugal membranes. Protein profiling was achieved by SDS-PAGE. ${ }^{29}$ The elemental compositions of the standard and purified $\alpha$-La protein fractions were determined by X-ray fluorescence (XRF), Spectro IQ II (Spectro Analytical Instruments, Germany).

To determine lactose content, HPLC analysis was performed using a Perkin-Elmer Series 200 HPLC (Shelton, CT) system with an Aminex HPX-87 H column with dimensions $300 \times 7.8 \mathrm{~mm}^{2}$. All the standard solutions and sample dilutions were prepared by $5 \mathrm{mM} \mathrm{H}_{2} \mathrm{SO}_{4}$, which was the used mobile phase. The column temperature was maintained at $45^{\circ} \mathrm{C}$ and the injection volume was $20 \mu \mathrm{L}$. The isocratic elution was performed at a flow rate of $0.6 \mathrm{~mL} / \mathrm{min}$. Analyses of the whey proteins were performed using the same HPLC system with an Agilent ACE C18 column with the dimensions of $150 \times 4.6 \mathrm{~mm}^{2}$. Experimental procedure was adapted from literature with some modifications. ${ }^{12}$ All the standard solutions and sample dilutions were prepared by $0.1 \%$ triflouroacetic acid (TFA) (v/v, in water), which was the mobile phase used in the HPLC. The mobile phases are of buffer A $0.1 \%$ TFA (v/v) in water, and of buffer B $0.09 \%$ TFA (v/v) in acetonitrile-water (80:20) (v/v). Elution was performed by the linear gradient program from 0 to $100 \% \mathrm{~B}$ in $40 \mathrm{~min}$ and then returned to starting conditions in $5 \mathrm{~min}$. The column temperature was maintained at $40^{\circ} \mathrm{C}$ and the flow rate was $1 \mathrm{~mL} / \mathrm{min}$ with the injection volume of $20 \mu \mathrm{L}$.

\section{$\alpha$-La hydrolysis, nanotube development, and AFM analysis}

Purified $\alpha$-La, $1 \%(\mathrm{w} / \mathrm{v})$ from WPI and $0.5 \%(\mathrm{w} / \mathrm{v})$ from WPC, was mixed with $4 \% \operatorname{BLP}(w / w)(B L P / \alpha-L a)$ in $75 \mathrm{mM}$ Tris- $\mathrm{HCl}$ buffer $(\mathrm{pH} 7.5)$. The ratio of calcium to 


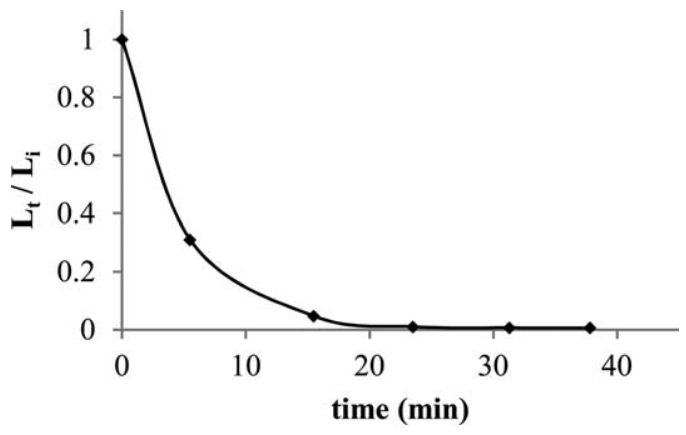

Figure 1. Removal of lactose in WPS retentate fractions by UF process.

$L_{\mathrm{i}}$ : initial lactose amount, and $L_{\mathrm{t}}$ : lactose amounts in the following fractions.

protein present natively in purified fractions were about $3\left(\mathrm{~mol} \mathrm{Ca}{ }^{2+} / \mathrm{mol} \mathrm{WPI-based} \alpha\right.$-La) and $5\left(\mathrm{~mol} \mathrm{Ca}{ }^{2+} / \mathrm{mol}\right.$ WPC-based $\alpha$-La) as determined from the XRF measurements. The reaction mixtures were incubated at $50^{\circ} \mathrm{C}$ for 1.5 $\mathrm{h}$ for the expected protein hydrolysis and nanotubular growth by self-assembly as reported previously. ${ }^{5,6}$ At the end of the incubation, samples were stored at $+4^{\circ} \mathrm{C}$ for further experiments. Hydrolysis and nanotube development using standard $\alpha$-La protein were also performed. ${ }^{6}$ Hydrolysis process was followed by HPLC using the same procedure given in the previous section. For microscopic observations, diluted (100fold) samples, taken from the reaction mixture at the end of the incubation, were placed onto glass surfaces. After drying, the structures were examined by AFM (MMSPM Nanoscope IV, Veeco, NY) in the tapping mode. A silicon AFM cantilever (Veeco, NY) with the properties; $f_{0}: 330-359 \mathrm{kHz}$ and $k$ : $12-103 \mathrm{~N} / \mathrm{m}$, was used.

\section{Raman and FT-IR spectroscopy}

Raman spectra of the purified $\alpha$-La fractions and $\alpha$-LaNTs were recorded by a confocal Raman system (S\&I Spectroscopy \& Imaging GmbH, Warstein, FRG, Germany) and FTIR analysis were performed using a Perkin-Elmer Spectrum 100 FT-IR Spectrometer (Perkin Elmer, Wellesley, MA) equipped with a horizontal ATR sampling surface ( $\mathrm{ZnSe}$ crystal) and a deuterated tri-glycine sulfate detector, using the procedure as reported previously. ${ }^{30}$ For the Raman measurements, a laser beam at $488 \mathrm{~nm}$ from an argon ion laser with $120 \mathrm{~mW}$ maximum power was used to excite samples. Typical resolutions varied between 1 and $10 \mathrm{~cm}^{-1}$ with a common slit width of $100 \mu \mathrm{m}$ at the entrance of the monochromator. Typical Raman data was recorded as the average of 100 scans accumulated per minute. Raman shifts were observed in the range of $100-4,000 \mathrm{~cm}^{-1}$. FT-IR measurements were taken in the range of $4,000-600 \mathrm{~cm}^{-1}$. The resolution was $4 \mathrm{~cm}^{-1}$ and 64 scan were recorded for each spectrum with a scan speed of $1 \mathrm{~cm} / \mathrm{s}$. A background spectrum was recorded before each sample measurement. Deconvolution of the data was performed with the parameters, $\gamma$ : 0.75 and $L: 15 \mathrm{~cm}$.

\section{Nanotubular gel formation and dye-binding assay}

Purified $\alpha$-La fractions and BLP mix were prepared as described previously. They were incubated in a rheometer (TA Instrument AR 2000ex, Elstree, Hertfordshire, UK) at $50^{\circ}$ C. Samples were subjected to dynamic oscillation with a strain of 0.005 at a frequency of $0.5 \mathrm{~Hz}$ during the incubation. ${ }^{6}$ Measurements were carried out with plane and cone geometry having a cone angle of 0.1 radians and a diameter of $25 \mathrm{~mm}$, in the time sweep mode. To remove loading effects, a preshear of $1 \mathrm{~s}^{-1}$ was applied for $1 \mathrm{~min}$ prior to further measurement.

To investigate the entrapment ability of a coloring agent within the $\alpha$-LaNT gels, UV-spectrophotometry assays were performed using Varioskan Flash (Thermo Fisher Scientific Inc., Waltham, MA). Samples were prepared by mixing protein nanotube solutions and congo red (CR) dye as a representative colorant. Control samples were also prepared by mixing $\alpha$-La proteins and dye. Fifty microliter (2.5\%) CR was added to $50 \mu \mathrm{L}$ protein /nanotube solution in well-plates and incubated in the instrument at $50^{\circ} \mathrm{C}$. Spectral scan for protein/nanotube solutions with $\mathrm{CR}$ were performed in the range of $400-700 \mathrm{~nm} .{ }^{31}$ As there is no sharp difference was observed at $498 \mathrm{~nm}$ or in another wavelength specific for CR or protein fibrils, $632 \mathrm{~nm}$ was selected within this visible range for spectrophotometric analyses. Measurements were taken at $632 \mathrm{~nm}$ with $1 \mathrm{~min}$-intervals for nearly $1 \mathrm{~h}$.

\section{Results and Discussion}

\section{$\alpha-L a$ purification by membrane process and chromatography}

As mentioned in the Materials section, protein and lactose concentrations were different in WPI and WP. Prior to chromatography, the main component of WP, lactose, was discarded during DF assisted UF. Figure 1 indicates clearly the decrease in the lactose amounts in the retentate fractions. Most of the lactose was removed in the first $(69 \%)$ and second $(26 \%)$ steps. Overall, the protein recovery was found as $94 \%$, and the lactose removal was found as $99.4 \%$ during this membrane process. UF assisted with DF is an effective process for lactose removal in whey and our results agree with the literature. ${ }^{4}$ The removal of lactose and some other nontarget molecules at the beginning was expected to lead more effective protein purification in whey by chromatography.

The anion-exchange elution approach based on the $\mathrm{pH}$ gradient was found to be very effective in separating $\alpha$-La and $\beta$-Lg fractions, even though the $\mathrm{pI}$ values of both proteins were close to each other. Figure 2 a shows the elution chromatogram of WPI and $2 b$ gives the protein profiles of the fractions collected by AEC and further purified by SEC. Four peaks (1-4) were obtained by elution with the buffer of $\mathrm{pH} 5.0$ (elution 1 fractions) attributable to $\beta$-Lg-rich fractions. The following two peaks (5-6) corresponds to $\alpha$-Larich fractions obtained by the elution with the buffer of $\mathrm{pH}$ 4.0 (elution 2 fractions). Further processing by SEC provided better purity for $\beta$-Lg (lane 8) and $\alpha$-La (lane 10) fractions.

Figure 3 represents fractionation of proteins in WPC. Five protein fractions were eluted. First three elution 1 fractions were $\beta$-Lg-rich fractions and the last elution 1 fraction (peak 4) was rich in $\alpha$-La. The fifth fraction, elution 2 fraction, was rich in $\beta$ - $\mathrm{Lg}$. The elution order of $\alpha$ - $\mathrm{La}$ and $\beta$ - $\mathrm{Lg}$ was not exactly as expected according to the separation approach. In WPC, $\beta$-Lg eluted first but not completely, then $\alpha$-La eluted with the same buffer ( $\mathrm{pH}$ 5.0) in the last fraction. The rest of $\beta$-Lg eluted by the next buffer ( $\mathrm{pH} 4.0)$. $\alpha$-La should have eluted after $\beta$-Lg with the buffer of $\mathrm{pH} 4.0$, instead of 



Figure 2. (a) Anion exchange chromatography patterns of WPI.

Unbound proteins (U) were eluted by $50 \mathrm{mM}$ Tris- $\mathrm{HCl}$, pH 6.0. Peak $1-4$ were eluted by $50 \mathrm{mM}$ Tris- $\mathrm{HCl}$, pH 5.0, and peaks 5 and 6 were eluted by Tris-HCl, pH 4.0. Column bed volume: $10 \times 2.5 \mathrm{~cm}(50 \mathrm{~mL}$ matrix); flow rate: $1 \mathrm{~mL} / \mathrm{min}$. (b) SDS-PAGE profiles of protein fractions of WPI. Lane M: protein ladder; lanes 1-6: fractions eluted by AEC (corresponding to peak 1-6); lanes 7-10: fractions eluted by SEC. Lanes 1-4: elution 1 fractions (El1F1, El1F2, El1F3, and El1F4); lanes 5 and 6: elution 2 fractions (El2F1, El2F2). Further purified fractions are seen in lane 7: El1F1/F, lane 8: El1F2/F, lane 9: El1F3/F, and lane 10: El1F4/F.


Figure 3. (a) Anion exchange chromatography patterns of WPC.

Unbound proteins (U) were eluted by $50 \mathrm{mM}$ Tris- $\mathrm{HCl}$, pH 6.0. Peak $1-4$ were eluted by $50 \mathrm{mM}$ Tris- $\mathrm{HCl}$, pH 5.0 , and peak 5 was eluted by Tris$\mathrm{HCl}$, pH 4.0. Column bed volume: $10 \times 2.5 \mathrm{~cm}(50 \mathrm{~mL}$ matrix); flow rate: $1 \mathrm{~mL} / \mathrm{min}$. (b) SDS-PAGE profiles of some protein fractions of WPC. Lane M: protein ladder, lanes 1-5: fractions eluted by AEC (corresponding to peaks 1-5); lanes 6-9: fractions eluted by SEC. Lanes 1-4: elution 1 fractions (El1F1, El1F2, El1F3, and El1F4), lane 5: elution 2 fraction (El2F). Further purified fractions in lane 6: El1F3/F1, lane 7: El1F3/F2, lane 8: El1F4/F1, lane 9: El1F4/F2.

$\mathrm{pH} 5.0$ according to its respective isoelectric point given in the literature. ${ }^{32}$ In WPI, some amount of $\alpha$-La also eluted by the buffer with $\mathrm{pH}$ 5.0, and last elution 1 fraction contained more $\alpha$-La besides $\beta$-Lg.

Some researchers eluted $\alpha$-La before $\beta$ - $\mathrm{Lg}$ as in reversed order in comparison with the same theory considered here. ${ }^{19}$ The reason for that was expressed by the incomplete binding of $\alpha$-La to the matrix due to competition and the greater selectivity of resin for $\beta$-Lg. Our findings also revealed that the binding of $\alpha$-La to the matrix was incomplete, especially in WPC, due to competition with the other minor components. Selective binding of $\beta$ - $\mathrm{Lg}$ to the matrix, which is parallel with the abundancy in whey, may also lead to this elution profile. It is clearly seen that, besides $\alpha$-La (target protein), $\beta-\mathrm{Lg}$ was also extracted from whey protein products by chromatography based on elution by changing $\mathrm{pH}$. Recovery of the proteins were $54.2 \%$ (WPI) and $74.4 \%$ (WPC) for AEC, and $71.4 \%$ (WPI) and $53.6 \%$ (WPC) for SEC, respectively. UF and centrifugal filtration techniques used to concentrate proteins in elution fractions prior to the final chromatographic step (e.g., SEC) may lead to protein losses. However, the protein recoveries obtained here are comparable with the current literature. ${ }^{14,19}$

Fundamental aim of this study was to obtain highly pure $\alpha$-La fractions free from $\beta$ - $\operatorname{Lg}$ to facilitate nanotube growth rather than a sole protein purification process. Nanotube formation can be easily disturbed by traces of $\beta$ - $\mathrm{Lg}$ in the main $\alpha$-La fractions and instead random aggregation might be induced instead. ${ }^{7}$ Therefore, high purity was essential for a successful nanotube formation and this goal was achieved by 




Figure 4. HPLC chromatograms of whey proteins.

Insets: (a) $\alpha$-La and $\beta$-Lg extracted from WPI (I- $\alpha$-La, I- $\beta$-Lg) and (b) $\alpha$-La and $\beta$-Lg extracted from WPC (C- $\alpha$-La, C- $\beta$-Lg).



Figure 5. Linearized logarithmic data of hydrolysis of $\alpha$-La protein with BLP.

$\mathrm{S}-\alpha-\mathrm{La}$ is the commercial standard of $\alpha$-La protein, I- $\alpha$-La and $\mathrm{C}-\alpha$-La are $\alpha$-La fractions extracted from WPI and WPC, respectively.

obtaining over $95 \%$ purity as indicated in Figures $2 \mathrm{~b}, 3 \mathrm{~b}$, and 4.

As seen in Figure 4, better resolution was achieved in the case of WPC compared to that of WPS. Both HPLC chromatograms and SDS-PAGE profiles confirmed that proteins were well-concentrated by UF. When WPI and other two chromatograms were compared, shifts in retention times of WPS and WPC were also observed. This can be attributed to the nature of the products due to the high mineral content. The peaks of $\alpha$-La and $\beta$-Lg extracted from WPI (Figure 4a) had much better resolution than the peaks of those extracted from WPC (Figure 4b), which reflected their sources. The purity of each $\alpha$-La and $\beta$-Lg fraction was determined from the ratio of their peak areas to the total peak area of all peaks obtained by HPLC. According to this, the purities of
WPI-based $\alpha$-La (I- $\alpha$-La) and $\beta$-Lg (I- $\beta$-Lg) were $95 \%$ and 97\% and WPC-based $\alpha$-La $(\mathrm{C}-\alpha-\mathrm{La})$ and $\beta$-Lg $(\mathrm{C}-\beta$-Lg) were both $99 \%$.

In XRF analyses, various minerals (magnesium, aluminum, manganese, calcium, and so forth) were detected in whey-based $\alpha$-La fractions as expected. These cations, especially calcium, are significant in nanotube elongation by acting as bridges between peptide units. ${ }^{33}$ Calcium amounts for standard (S) and purified $\alpha$-La fractions were as follows: $27.6 \mathrm{ppm}(\mathrm{S}-\alpha-\mathrm{La}, 3 \%), 74.6 \mathrm{ppm}$ (I- $\alpha$-La, 1\%), and 108 ppm (C- $\alpha$-La, $0.5 \%)$. Calcium contents in the purified $\alpha$-La fractions, especially in $\mathrm{C}-\alpha$-La, were quite high when compared to that in the standard $\alpha$-La. Besides calcium, the amounts of other minerals were also higher in purified proteins (data not shown). These native elemental composition of the $\alpha$-La samples is expected to be highly effective in the nature of the nanostructures to be developed.

\section{Protein hydrolysis and nanotube formation from purified $\alpha-L a$}

Enzymatic hydrolysis is the first step toward developing self-assembled protein nanotubes. BLP enzyme is a serine endoprotease specific for peptide bonds with glutamic and aspartic acid residues. ${ }^{33}$ It cuts the protein at these specific sites and self-association of the resulting peptides leads to nanotube formation. ${ }^{33}$ Digestion of $\alpha$-La proteins (both standard and purified) were indicated in Figure 5. A linear relation was noticed during the hydrolysis of $\alpha$-La with BLP and this was described by the first-order kinetics, as reported previously. ${ }^{6}$ Data obtained by the hydrolysis of standard $\alpha$-La protein $(S-\alpha$-La) and I- $\alpha$-La were best fitted when compared to those of $\mathrm{C}-\alpha$-La. In all three samples, enzyme to protein ratio was constant but amount of calcium was different. It was considerably higher in C- $\alpha$-La. It was demonstrated that calcium had no effect in hydrolysis kinetics when examined with changing calcium to protein ratio $(R)$ up to $3 .^{6}$ Our findings are also comparable with this. In the 

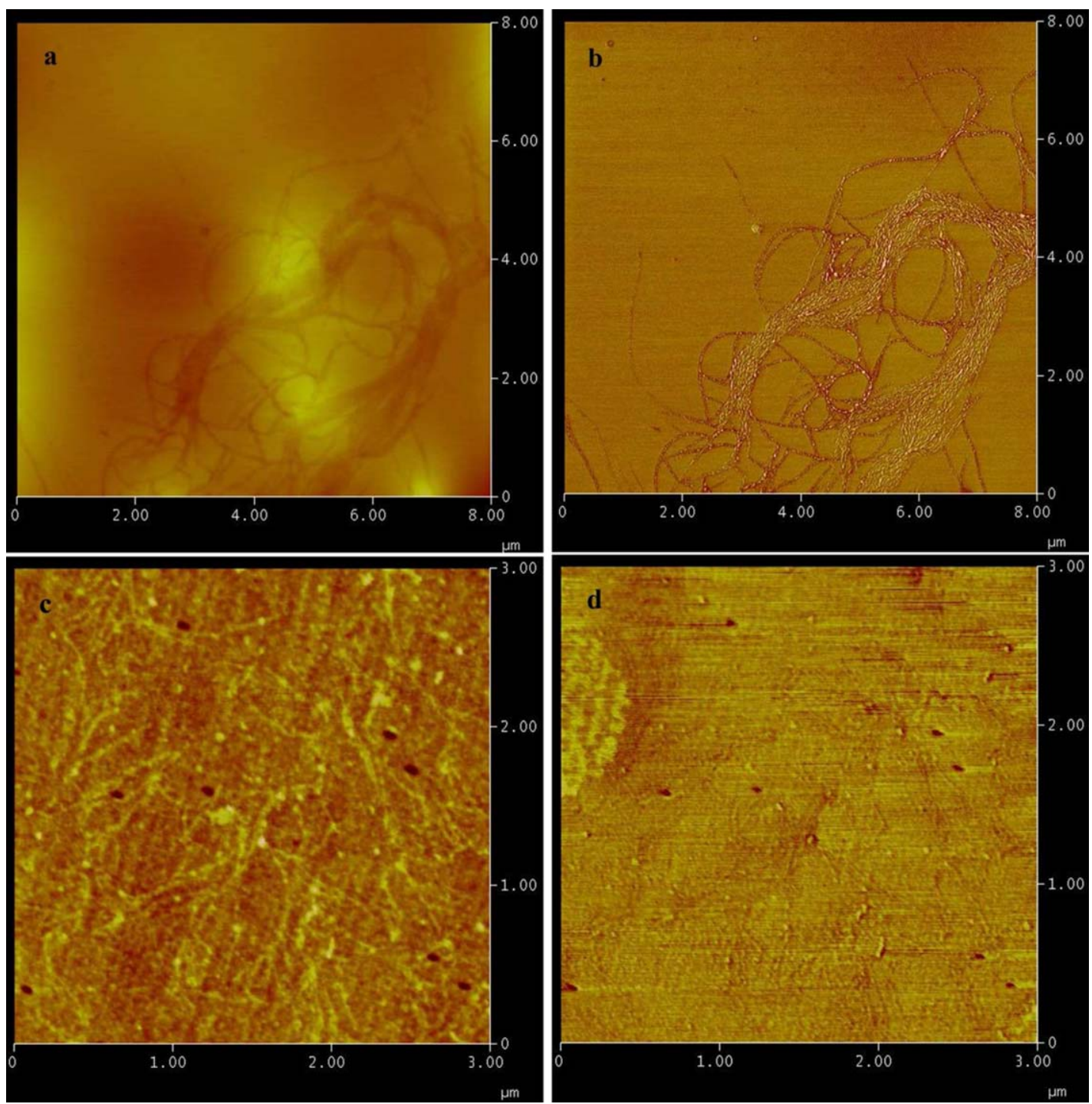

Figure 6. AFM images of nanotubes constructed by purified $\alpha$-La proteins (a, b) WPI-based $\alpha$-La nanotubes (I- $\alpha$-LaNTs); (c, d) WPCbased $\alpha$-La nanotubes $(\mathrm{C}-\alpha$-LaNTs).

$(a, c)$ Height images; (b, d) Phase images.

case of $\mathrm{S}-\alpha-\mathrm{La}(R=2)$ and $\mathrm{I}-\alpha-\mathrm{La}(R=3), R^{2}$ was about 0.99. However, the effect of calcium with higher concentrations in hydrolysis kinetics was not reported. For C- $\alpha$-La $(R=5)$, when the final data point, taken at the end of hydrolysis, was eliminated, $R^{2}$ was calculated as 0.95 . If this data point was not eliminated, the linearity declined and $R^{2}$ value decreased. This may be due to a decrease in the enzyme activity after a certain period of hydrolysis, as the protein to be hydrolyzed was depleted due to the presence of such a high amount of calcium in the medium.

Figure 6 shows the AFM images of protein nanotubes developed by self-assembly after partial hydrolysis of purified $\alpha$-La fractions. The $\alpha$-LaNTs formed by WPI-based $\alpha$-La (I- $\alpha$-LaNTs) presented chain-like, long tubular structures with a uniform width of about $20 \mathrm{~nm}$ (Figures 6a,b). However, the images of those formed by WPC-based $\alpha$-La $(\mathrm{C}-\alpha-$ LaNTs) show thinner fibrils leading to reticular structures (Figures 6c,d).

Previous studies reported $\alpha$-LaNTs with the dimensions of $20 \mathrm{~nm}$ in width and one to few microns in length. ${ }^{5,6}$ The constructed nanotubules in our studies (I- $\alpha$-LaNTs) were longer than these in the literature with chain-like nature. This finding indicates that these nanotubules may have the ability for formation of stronger networks to be useful in application.

The differences in the appearance of the nanostructures developed by I- $\alpha$-La and C- $\alpha$-La are most probably due to the protein concentration and cation content of the protein solutions used. Three percent of protein $(\mathrm{w} / \mathrm{v})$ and $R=3$ (mol $\mathrm{Ca}^{2+}$ ions/mol $\alpha$-La) were given as the optimum values for nanotube development from $\alpha$-La. ${ }^{6}$ Fuzziness of the strands was induced upon increased cation amounts $(R \geq 10)$ at $1 \%$ protein concentration. ${ }^{5}$ In this study, $1 \%$ protein and $R=3$ were used for formation of nanotubules from I- $\alpha$-La and $0.5 \%$ protein and $R=5$ were used for formation of nanotubules from $\mathrm{C}$ - $\alpha$-La. Additionally, trace amount of other cations (sodium, magnesium, and so forth) present natively in the purified $\alpha$-La fractions may affect selfassembly process by increasing cation concentration in the medium. The appearance and dimensions of the nanostructures and also the resultant architecture were influenced by different concentrations of cation and protein. It was also 
reported that fibrillar structures with $5 \mathrm{~nm}$ width were formed when the protein concentration of $\alpha$-La was $\leq 1 \%$ due to the aggregation of $8.8 \mathrm{kDa}$ peptide fragments obtained by hydrolysis. ${ }^{34}$ Especially in the case of WPCbased $\alpha$-La, fibril formation might be induced mostly instead of nanotube growth. Nanotubes developed using commercial standard of $\alpha$-La protein have been reported elsewhere. ${ }^{30}$

\section{Structural characterization of $\alpha-L$ a fractions and $\alpha-L a N T s$}

Conformational changes in the protein native structure were investigated with spectroscopical methods. Raman spectra of the purified $\alpha$-La proteins and their nanotubes were given in Figure 7. For I- $\alpha$-La, amide I band appeared at $1,661 \mathrm{~cm}^{-1}$ was attributed mainly to the $\alpha$-helix structure, ${ }^{20}$ whereas in the case of I- $\alpha$-LaNTs, $\beta$-sheets become

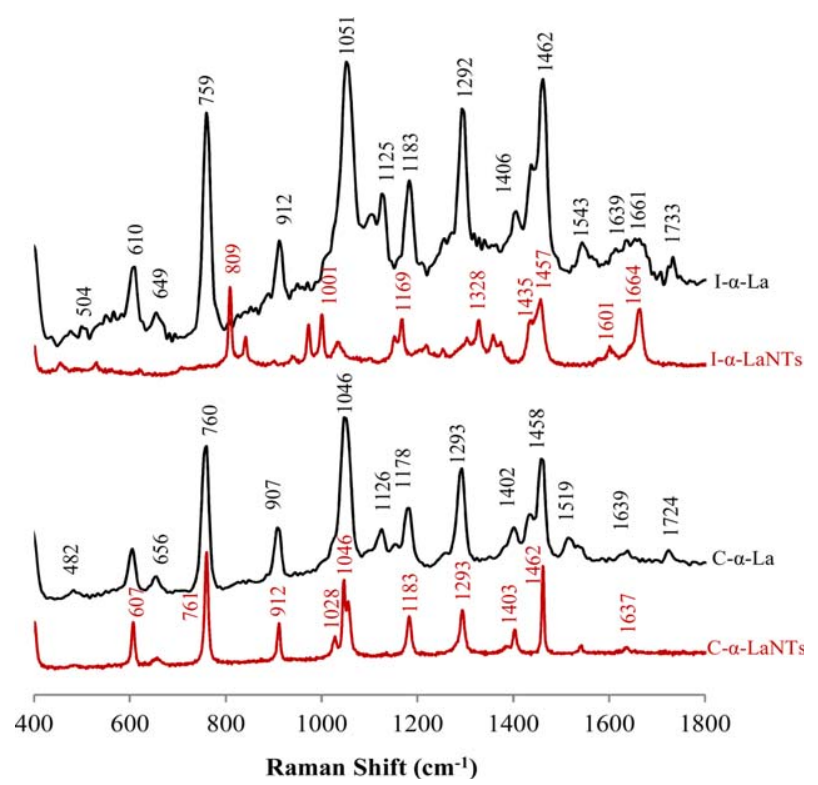

Figure 7. Raman spectra of the purified $\alpha$-La proteins (I- $\alpha$-La, C- $\alpha$-La) and their nanotubes (I- $\alpha$-LaNTs, C- $\alpha$ LaNTs).

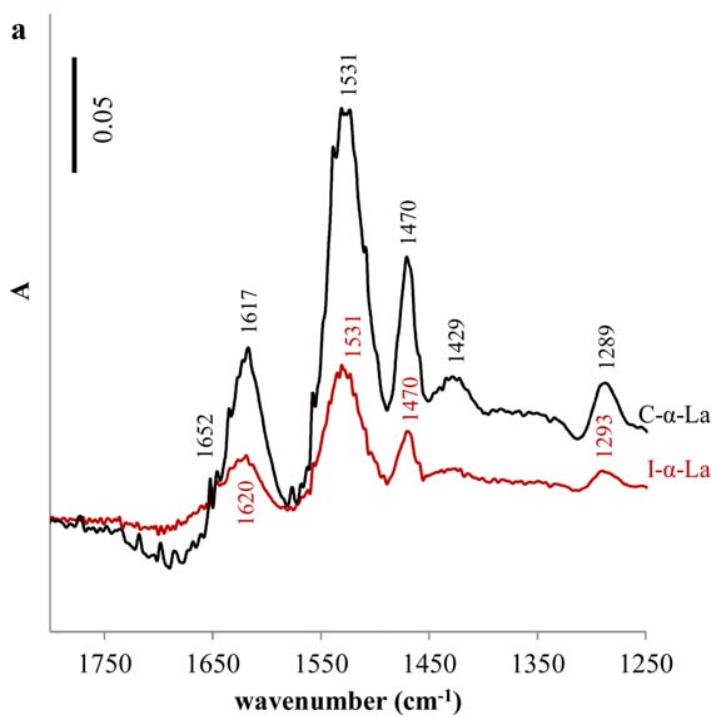

dominant as evident by the band at $1,666 \mathrm{~cm}^{-1} 35$ However, amide I band at $1,639 \mathrm{~cm}^{-1}$, and amide III band at $1,292 \mathrm{~cm}^{-1}$ were predicted as the indicating features that unordered structures and $\beta$-turns were dominant in the secondary structure of $\mathrm{C}-\alpha$-La. ${ }^{36}$ The difference in the most important conformational sensitive region, amide I, of two $\alpha$-La samples may be explained as follows. Protein native structure, especially in $\mathrm{C}-\alpha$-La, might have been distorted during purification steps and this may have led to shift in amide I band. Also, Raman active bands might not be allowed due to cation chelation. This conformational difference in the structure may affect hydrolysis, self-assembly process, and formation of the nanostructures. Tyrosine and phenylalanine and tryptophan residues were visible in the structures of both $\alpha$-La proteins, evident from the peaks at $1,183 / 1,178,1,125 / 1,126$, and $759 / 760 \mathrm{~cm}^{-1}$. 37 The $\mathrm{S}-\mathrm{S}$ stretching mode gives Raman signals between 480 and $510 \mathrm{~cm}^{-1} 38$ and disulfide bands were detected at 504 and $482 \mathrm{~cm}^{-1}$ in I- $\alpha$-La and C- $\alpha$-La Raman data, respectively. In both nanotube spectra, various shifts, peak losses and new peaks were observed most probably due to rearrangement of the peptides into nanotubes and fibrils.

FT-IR spectra of purified $\alpha$-La fractions and nanotubes are given in Figure 8. Aggregated strands $\left(1,617 / 1,620 \mathrm{~cm}^{-1}\right)$ and $\alpha$-helices $\left(1,287 / 1,293 \mathrm{~cm}^{-1}\right)$ were dominant in $\alpha$-La samples. $^{39,40}$ In the case of nanotubes, $\beta$-sheets and turns were appeared as indicated by the peaks greater than $1,660 \mathrm{~cm}^{-1}$. The peaks at $1,559 / 1,403 \mathrm{~cm}^{-1}$, seen in the nanotube spectra, indicates Asp and Glu sites revealed during hydrolysis and most probably available for cation binding during nanotube elongation. Detailed FT-IR and Raman analysis for the investigation of structural changes in $\alpha$-La protein standard during nanotube formation have been published recently. ${ }^{30}$

\section{$\alpha-L a N T$ gelation and color-binding capability of the gels}

Gel formation ability of $\alpha$-LaNTs were investigated for potential food applications. Storage modulus $\left(G^{\prime}\right)$ curves of nanotube triggered gel formation of $\alpha$-La proteins (standard and purified) are shown in Figure 9. Gelation was defined at the point that $G^{\prime}$ is greater than $1 .^{6}$ Gelation was started at

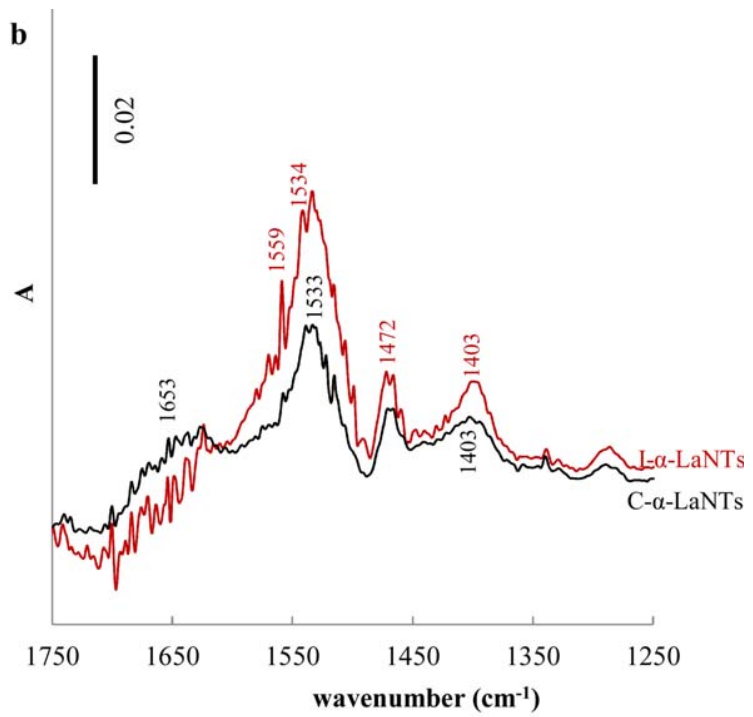

Figure 8. Fourier-self deconvolved spectra of (a) purified $\alpha$-La proteins (I- $\alpha$-La, C- $\alpha$-La) and (b) nanotubes constructed from purified $\alpha$-La proteins (I- $\alpha$-LaNTs and C- $\alpha$-LaNTs). 
nearly 50th min for S- $\alpha$-LaNTs and I- $\alpha$-LaNTs and 20th min for $\mathrm{C}-\alpha$-LaNTs during their growth. Protein and calcium concentrations of the samples were different. Therefore, gelation process occurred differently with different gel microstructure in each sample. Clear, transparent, and viscoelastic gels were obtained by the formation of nanotubes of standard protein. However, white, turbid, and stiffer gels were observed by the

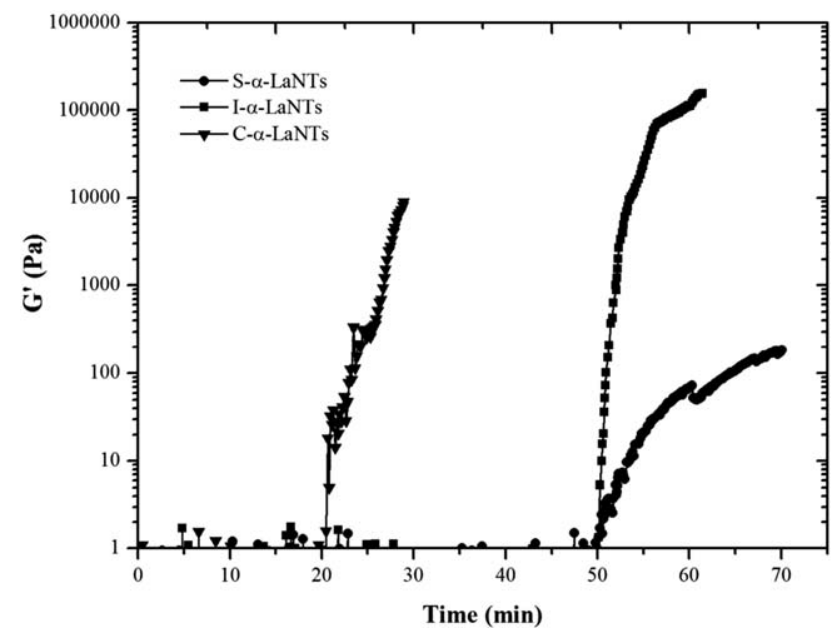

Figure 9. Storage modulus, $G^{\prime}$ data obtained as a function of time during nanotube triggered gelation of the standard and purified $\alpha$-La proteins.

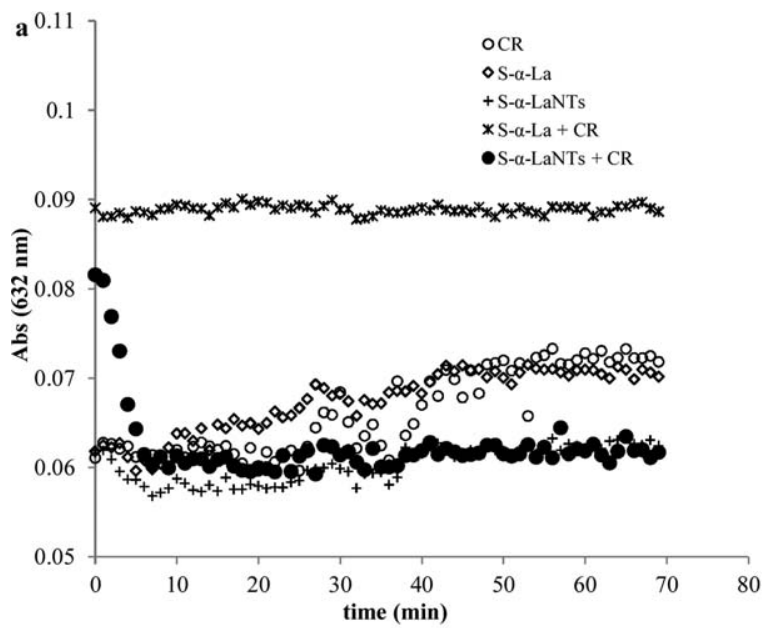

growth of I- $\alpha$-LaNTs. Although protein concentrations were different in S- $\alpha$-LaNTs (3\%) and I- $\alpha$-LaNTs (1\%), gelation was started nearly at the same time for both samples. However, the resultant gel was stronger in the latter. Gelation time detected using C- $\alpha$-La sample was shorter than the others. But no desirable gelation was achieved. Mostly aggregation occurred due to its high mineral content, natively. There were some breaks observed in $G^{\prime}$ curves. Measurements were taken continuously by the instrument during the process under the same conditions for all three samples. Therefore, the differences may have arose from the natural composition of the protein samples, especially the purified ones. Also, $G^{\prime}$ values of purified samples, especially I- $\alpha$-La, was very high when compared with the standard sample. This may be due to drying out, occurred in the samples after some time during incubation at $50^{\circ} \mathrm{C}$, although the samples were placed in the sample holder with closed chamber. Under these considerations, $G^{\prime}$ curves presented in Figure 9 were used to observe the differences in gelation times and profiles of these three protein samples due to their protein and calcium contents.

During $\alpha$-LaNT-triggered gelation process, initial structure formation could be facilitated by calcium ions resulting in stiffer tubular structures due to ionic interactions. ${ }^{41}$ At high calcium concentrations, more random aggregates were induced, and this gave rise to formation of turbid gels. ${ }^{6}$ Both protein and cation concentrations critically affect gel structure and strength. This may be desirable for some applications.

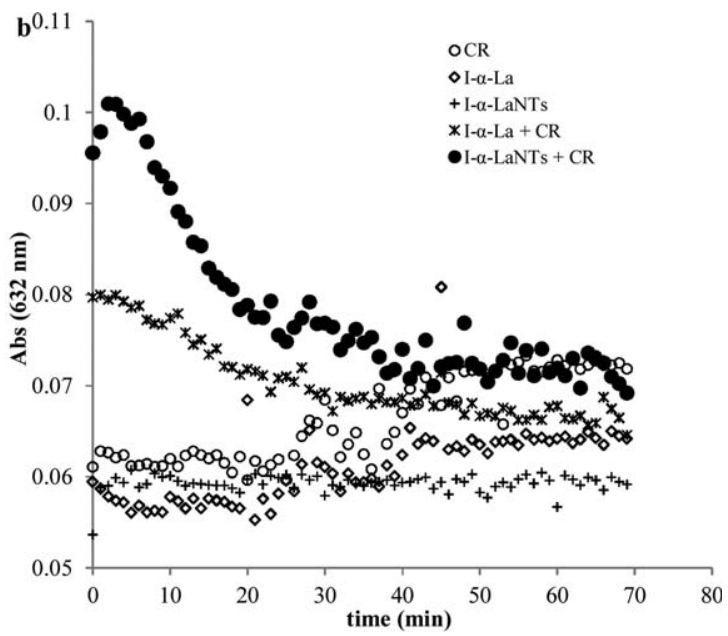

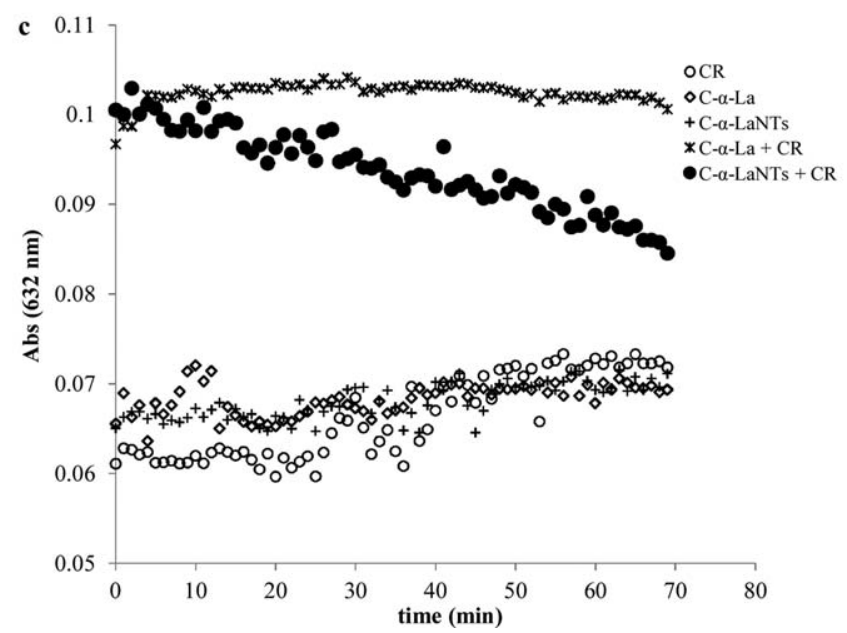

Figure 10. Color-binding capabilities of the nanotubular gels formed by standard (a) and purified (b, c) $\alpha$-La proteins. 
The $\alpha$-La NT/fibrillar gels were also investigated for their dye binding capabilities. This capability can be considered as an important application area for them in food processing such as addition and stabilizing of coloring agents in food products. $\mathrm{CR}$ was chosen as a representative coloring agent for this assay. Figure 10 presents incubation periods of protein and nanotube samples mixed with CR in UV spectrophotometer. Absorbance values gradually decreased when the dye and nanotubes were mixed and incubated. However, in the other cases, that are the incubation of protein and dye mixture or incubation of all elements individually, such a clear trend was not observed. Visual observations and the UV measurements indicated that the dye was absorbed by the gels of $\alpha$-LaNTs/fibrils uniformly by inducing transparency. The nanotubes formed by standard protein had desirable protein and calcium concentrations, but purified ones were lower in protein and higher in calcium. This gave rise to observe a better trend in standard protein nanotubes and dye mixture. When compared, I- $\alpha$-LaNTs/CR mixture indicated better trend than $\mathrm{C}-\alpha$-LaNTs/CR due to compositional difference. The gel of the former was clearer than that of latter having nonuniform aggregates at the bottom of the gels.

Birefringence of amyloid fibrils was investigated by staining with $\mathrm{CR}$ dye and potential interactions between fibrils and CR were reported. ${ }^{31}$ The differences in the formation of fibrils of native and modified $\beta$ - $\mathrm{Lg}$ by dye-binding assay in spectroscopy using CR were also investigated. ${ }^{42}$ From the knowledge of binding of CR dye to protein fibrils, although the interaction mechanism was not well understood, ${ }^{31}$ spectroscopic assay, presented in this study, indicated that adsorption of $\mathrm{CR}$ dye in the case of nanotubes/fibrils were very clear when compared to those for the control samples. In our future studies, the effects of CR on the self-assembled structures of nanotubules/fibrils will also be investigated. Our preliminary findings reveal that self-assembled $\alpha$-La nanotubular gels are promising in entrapment and carrying of coloring agents. These characteristics can be used for various applications in food and bioprocessing.

\section{Conclusions}

In this study, we presented the purification of $\alpha$-La from whey products to form nanotubular/fibrillar structures to be used as functional ingredients in processing. The method used, consisting of a strong anion exchanger, Q-sepharose, in combination with the elution approach based on changing $\mathrm{pH}$, was shown to be a very effective and promising method in separating major proteins $(\alpha-\mathrm{La}$ and $\beta$-Lg) in whey products with high purity. Protein hydrolysis prior to nanotubular assembly indicated that calcium amount did not affect hydrolysis kinetics up to a certain ratio $(R=3)$ as reported previously. However, some differences were observed with the possible adverse effect of higher calcium concentrations $(R=5)$ through the end of hydrolysis. The appearance and dimensions of the nanostructures developed by WPI- and WPC-based $\alpha$-La were different due to the differences in native composition of the purified fractions. I- $\alpha$-La formed long chain-like nanotubules, whereas, $\mathrm{C}-\alpha$-La formed shorter fibril-like nanostructures. Spectrophotometric data exhibited that the secondary structure of $\alpha$-La was mainly in $\alpha$-helix with aggregated strands. But some conformational changes was noticeable, especially in C- $\alpha$-La, most probably due to structural disturbances during purification. Conformational changes also occurred during nanotube growth depending on rearrangement of the peptides into nanotubules or fibrils. Nanotube/fibril formation triggers gelation, and both protein and calcium concentrations are critical parameters in gel formation, its structure, and appearance. The gel, obtained during formation of I- $\alpha$-LaNTs, is much more desirable than $\mathrm{C}-\alpha$-LaNTs. The gel matrix entrapped a coloring agent with transparent appearance. Therefore, $\alpha$-La nanotubular gels can be enriched with natural colorants for various applications in food processing. Detailed analysis of the gelation process triggered by $\alpha$-La nanotubules/fibrils and studies on the other food applications (e.g., encapsulation) of these food-grade nanoparticles are also underway.

This study can be considered as a primary model reporting development of a functional ingredient from a waste material. Further studies will include standardization of purified $\alpha$-La fractions to develop desirable nanotubules and nanotubular gels for targeted purposes.

\section{Acknowledgments}

The Authors would like to thank Assist. Prof. Dr. Enver Tarhan and Assoc. Prof. Dr. Banu Özen for their help in Raman and FT-IR analyses, respectively. Special thanks to Iztech Biotechnology Research Lab for purification studies and all background works of the presented experiments. Also, they thank to Iztech Center for Material Research for AFM analyses and Professor Metin Tanoğlu for analysis in Rheometer. This work was supported financially by The Scientific and Technological Research Council of Turkey (project no: 1090866, 2010-2011) and İzmir Institute of Technology, Scientific Research Projects fund (project no: IYTE03, 2009-2011).

\section{Literature Cited}

1. Zhang S. Emerging biological materials through molecular selfassembly. Biotechnol Adv. 2002;20:321-339.

2. Vauthey S, Santoso S, Gong H, Watson N, Zhang S. Molecular self-assembly of surfactant-like peptides to form nanotubes and nanovesicles. PNAS Biophys. 2002;99 (8):5355-5360.

3. Chen P. Self-assembly of ionic-complementary peptides: a physicochemical viewpoint. Colloids Surf A. 2005;261:3-24.

4. Zydney AL. New separations using membrane filtration: new opportunities for whey fractionation. Int. Dairy J. 1998;8:243250.

5. Ipsen R, Otte J, Qvist KB. Molecular self-assembly of partially hydrolysed a-lactalbumin resulting in strong gels with a novel microstructure. J Dairy Res. 2001;68:277-286.

6. Graveland-Bikker JF, Ipsen R, Otte J, de Kruif CG. Influence of calcium on the self-assembly of partially hydrolyzed $\alpha$-lactalbumin. Langmuir. 2004;20:6841-6846.

7. Graveland-Bikker JF, de Kruif CG. Unique milk protein based nanotubes: food and nanotechnology meet. Trends Food Sci Technol. 2006; 17:196-203.

8. Aschaffenburg R, Drewry J. Improved method for the preparation of crystalline beta-lactoglobulin and alpha-lactalbumin from cow's milk. Biochemistry. 1957;65:273-277.

9. Mailliart P, Ribadeau-Dumas B. Preparation of $\beta$-Lactoglobulin and $\beta$-Lactoglobulin-free proteins from whey retentate by $\mathrm{NaCl}$ salting out at low pH. J Food Sci. 1988;53:743-745.

10. Bramaud C, Aimar P, Daufin G. Whey protein fractionation: isoelectric precipitation of $\alpha$-lactalbumin under gentle heat treatment. Biotechnol Bioeng. 1997;56:391-397.

11. Lucena EM, Álvarez S, Menéndez C, Riera FA, Álvarez R. $\alpha$ Lactalbumin precipitation from commercial whey protein concentrates. Sep Purif Technol. 2007;52:446-453.

12. Fernández A, Menéndez V, Riera FA, Álvarez R. Caseinomacropeptide behaviour in a whey protein fractionation process 
based on $\alpha$-lactalbumin precipitation. J Dairy Res. 2011;78:196202.

13. Cheang B, Zydney AL. Separation of $\alpha$-lactalbumin and $\beta$ lactoglobulin using membrane ultrafiltration. Biotechnol Bioeng. 2003;83:201-209.

14. Konrad G, Kleinschmidth T. A new method for isolation of native $\alpha$-lactalbumin from sweet whey. Int Dairy J. 2008;18:4754.

15. Kristiansen KR, Otte J, Ipsen R, Qvist KB. Large scale preparation of $\beta$-lactoglobulin $\mathrm{A}$ and $\mathrm{B}$ by ultrafiltration and ionexchange chromatography. Int Dairy J. 1998;8:113-118.

16. Ye X, Yoshida S, Ng TB. Isolation of lactoperoxidase, lactoferrin, $\alpha$-lactalbumin, $\beta$-lactoglobulin $\mathrm{B}$ and $\beta$-lactoglobulin $\mathrm{A}$ from bovine rennet whey using ion exchange chromatography. Int J Biochem Cell Biol. 2000;32:1143-1150.

17. Neyestani TR, Djalali M, Pezeshki M. Isolation of $\alpha$ lactalbumin, $\beta$-lactoglobulin, and bovine serum albumin from cow's milk using gel filtration and anion-exchange chromatography including evaluation of their antigenicity. Protein Expr Purif. 2003;29:202-208.

18. Doultani S, Turhan KN, Etzel MR. Fractionation of proteins from whey using cation exchange chromatography. Process Biochem. 2004;39:1737-1743.

19. Gerberding SJ, Byers CH. Preparative ion-exchange chromatography of proteins from dairy whey. J Chromatog A. 1998;808: 141-151.

20. Liang M, Chen VYT, Chen HL, Chen W. A simple and direct isolation of whey components from raw milk by gel filtration chromatography and structural characterization by Fourier transform Raman spectroscopy. Talanta. 2006;69:1269-1277.

21. Santos MJ, Teixeira JA, Rodrigues LR. Fractionation of the major whey proteins and isolation of $\beta$-Lactoglobulin variants by anion exchange chromatography. Sep Purif Technol. 2012; 90:133-139.

22. Tu AT. Peptide backbone conformation and microenvironment of protein side chains. In: Clark RJH, Hester RE, editors. Spectroscopy of Biological Systems. New York: Wiley, 1986:47-112.

23. Dickinson E, Yamamoto Y. Rheology of milk protein gels and protein-stabilized emulsion gels cross-linked with transglutaminase. J Agric Food Chem. 1996;44:1371-1377.

24. Ju ZY, Otte J, Zakora M, Qvist KB. Enzyme-induced gelation of whey proteins: effect of protein denaturation. Int Dairy J. 1997:7:71-78.

25. Kavanagh GM, Clark AH, Gosal WS, Ross-Murphy SB. Heatinduced gelation of $\beta$-lactoglobulin/ $\alpha$-lactalbumin blends at $\mathrm{pH}$ 3 and pH 7. Macromolecules. 2000;33:7029-7037.

26. Lorenzen PC, Schrader K. A comparative study of the gelation properties of whey protein concentrate and whey protein isolate. Lait. 2006;86:259-271.

27. Loveday SM, Rao MA, Creamer LK, Singh H. Factors affecting rheological characteristics of fibril gels: the case of $\beta$ lactoglobulin and $\alpha$-lactalbumin. J Food Sci. 2009;74:47-55.
28. Otte J, Lomholt SB, Ipsen R, Stapelfeldt H, Bukrinsky JT, Qvist KB. Aggregate formation during hydrolysis of $\beta$-lactoglobulin with a Glu and Asp specific protease from Bacillus licheniformis. J Agric Food Chem. 1997;45:4889-4896.

29. Laemmli UK. Cleavage of structural proteins during the assembly of the head of bacteriophage T4. Nature. 1970;227:680-685.

30. Tarhan Ö, Tarhan E, Harsa S. Investigation of the structure of alpha-lactalbumin protein nanotubes using optical spectroscopy. J Dairy Res. 2014;81:98-106.

31. Nilsson MR. Techniques to study amyloid fibril formation in vitro. Methods. 2004;34:151-160.

32. Ounis WB, Gauthier SF, Turgeon SL, Roufik S, Pouli Y. Separation of minor protein components from whey protein isolates by heparin affinity chromatography. Int Dairy J. 2008;18:10431050.

33. Ipsen R, Otte J. Self-assembly of partially hydrolysed $\alpha$-lactalbumin. Biotechnol Adv. 2007;25:602-605.

34. Otte J, Ipsen R, Bauer R, Bjerrum MJ, Waninge R. Formation of amyloid-like fibrils upon limited proteolysis of bovine $\alpha$-lactalbumin. Int Dairy J. 2005;15:219-229.

35. Miura T, Thomas GJ Jr. Raman Spectroscopy of Proteins and Their Assemblies. In: Biswas BB, Roy S, editors. Subcellular Biochemistry (Proteins: Structure, Function and Engineering). New York: Plenum, 1995:55-99.

36. Bandekar J, Krimm S. Vibrational analysis of peptides, polypeptides, and proteins: characteristic amide bands of $\beta$-turns. Proc Natl Acad Sci USA. 1979;76:774-777.

37. Ashton L, Blanch EW. pH-induced conformational transitions in $\alpha$-lactalbumin investigated with two-dimensional Raman correlation variance plots and moving windows. J Mol Struct. 2010; 947:132-138.

38. Pelletier MJ, Pelletier CC. Spectroscopic theory for chemical imaging. In: Sasic S, Ozaki Y, editors. Raman, Infrared, and Near-Infrared Chemical Imaging. New Jersey: Wiley, 2010:120.

39. Anderle G, Mendelsohn R. Thermal denaturation of globular proteins Fourier transform-infrared studies of the amide III spectral region. Biophys J. 1987;52:69-74.

40. Kong J, Yu S. Fourier transform infrared spectroscopic analysis of protein secondary structures. Acta Biochim Biophys Sin. 2007:39:549-559.

41. Ipsen R, Otte J, Qvist KB. Protease-induced nano-tubular gels from $\alpha$-lactalbumin. In: Dickinson E, Vliet TV, editors. Food Colloids, Biopolymers and Materials. London: RSC Publishing, 2003:84-92.

42. Ghadami SA, Khodarahmi R, Ghobadi S, Ghasemi M, Saeed Pirmoradi S. Amyloid fibril formation by native and modified bovine $\beta$-lactoglobulins proceeds through unfolded form of proteins: a comparative study. Biophys Chem. 2011;159:311-320.

Manuscript received Mar. 7, 2014, and revision received Jul. 11, 2014. 